DigiTALCOMMONS @WAYNESTATE-
Michigan Journal of Counseling:

Research, Theory and Practice

Volume 30 | Issue 1

Article 3

$2-1-2002$

\title{
An Exploration of Compassion Fatigue in Novice Counselors
}

Herbert A. Exum

North Carolina State University

Follow this and additional works at: https://digitalcommons.wayne.edu/mijoc

\section{Recommended Citation}

Exum, H. A. (2002). An Exploration of Compassion Fatigue in Novice Counselors, Dimensions of Counseling, 30(1), 10-14. doi: $10.22237 / \mathrm{mijoc} / 1012521720$

This Article is brought to you for free and open access by the Open Access Journals at DigitalCommons@WayneState. It has been accepted for inclusion in Michigan Journal of Counseling: Research, Theory and Practice by an authorized editor of DigitalCommons@WayneState. 


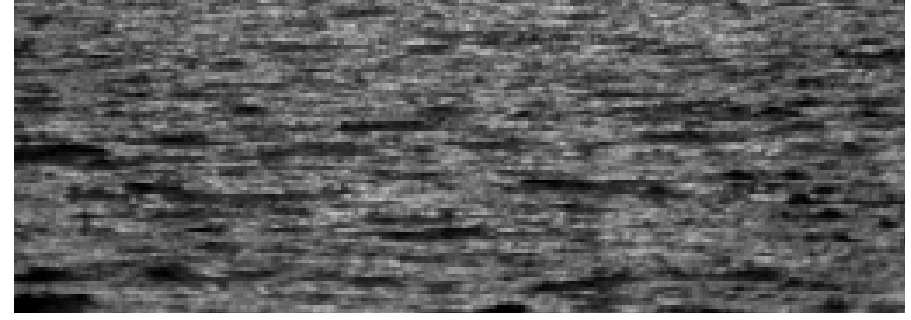

\section{An Exploration of Compassion Fatigue in Novice Counselors}

\section{Herbert A. Exum, Ph.D.}

North Carolina State University
Compassion fatigue is one of the various forms of suboptimal performance novice counselors may demonstrate. Like burnout, it is a type of impairment that disrupts the counselor's ability to establish and maintain therapeutic relationships. One of the responsibilities of the clinical supervisor is to determine effective methods of early identification and prevention of this phenomenon. This article will discuss compassion fatigue, related concepts, and strategies clinical supervisors may use to address it.

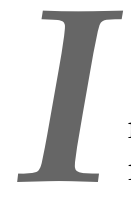

ndividuals are drawn to counseling as a profession for many reasons including purely altruistic motives. Very often, however, individuals are drawn to the profession to provide for others the care and understanding that they did not receive (Perlman, 1999).

Elliot and Guy (1993) found that many therapists are themselves survivors of family disruption and early trauma. Similarly, White and Franzoni's (1990) multidimensional analysis of the mental health of graduate counselor trainees concluded that counselor trainees had higher levels of psychological disturbance than the members of the general population. In addition to coming into the profession with already existing issues, counselors may also find themselves burdened by the practice of attaching to client issues. Within this context Stadler, Willing, Eberhage, and Ward (1988) concluded that clinical supervisors should work to prevent counselor impairment by reducing the ways in which the practice of counseling contributes to impairment. Accordingly, one important task for supervisors is to teach novice counselors how to process their own feelings about their clients without becoming over-involved in their lives.

This may be particularly difficult for the novice counselor working with clients who have survived severe traumas. 
Working with trauma survivors may very easily produce symptoms of burnout in novice counselors for several reasons. First, trauma survivors tend to present the counselor with a host of chronic symptoms that are resistant to change and difficult to treat (Perlman, 1999). Second, they almost always require longterm counseling especially since trauma survivors then to be reluctant to focus on their own traumatic memories. Finally, trust and betrayal issues involved in traumatization may tend to increase the length of time needed for counselors to form the therapeutic alliance (McCann and Pearlman, 1990). All of these conditions may be frustrating and potentially discouraging for the novice counselor and could easily confront even the most seasoned counselor with his or her own emotional limitations (Perlman, 1999).

\section{Overview}

\section{Symptoms}

Novice counselors who work with trauma survivors commonly report experiencing a variety of feelings similar to those of their clients. Somatic symptoms such as headaches, nausea, and sleeplessness, intrusive images, difficulty trusting others, emotional numbing and sexual difficulties are common responses (Neuman and Gamble, 1995). The individual essentially experiences the environment and other people in the same way that the trauma survivor experiences them. This should not be confused with empathy since this process is neither voluntary nor under the direct control of the counselor.

One interpretation is that these responses are a form of trainee impairment (Forrest, Elman, Gizara and VachaHasse, 1999). However, Neuman and Gamble suggest that these symptoms represent the expected reaction to trauma work. This phenomenon has been called traumatic countertransference (Herman, 1992); secondary traumatization (Munroe, Shay, Fisher, Makary,

Rappoport, and Zimering, 1999); vicarious traumatization (Perlman \& Saakvitne, 1995) or compassion fatigue by Figley (1985). Compassion fatigue as defined by Figley is a state of tension and preoccupation with the individual or cumulative trauma of clients as manifested in either reexperiencing the traumatic events, avoidance or numbing of reminders of the traumatic event or persistent emotional arousal. Figley (1985) stated that it is essentially the absorption and retention of the emotional suffering of others thereby causing a form of impairment. Neumann and Gamble (1995) extended Figley's definition by adding that it is negative transformation of the counselor's inner experience that results in a disruption in the counselor's worldview and sense of identity.

\section{Related Concepts}

Neumann and Gamble (1995) suggested that compassion fatigue is not only related to countertransference and often intertwined with it, but it may also be a precursor to burnout. They suggested that it eventually produces emotional exhaustion, depersonalization, and reduced feelings of personal accomplishment. These states are the three major components of burnout as conceptualized by Maslach and Jackson (1986). McCann and Pearlman (1990) stated that vicarious traumatization or compassion fatigue is more adequate than either burnout or countertransference in describing what happens to counselors who began to experience the internal lives of their traumatized clients. In their conception, the counselor's cognitive schema about the self and the world are altered during the course of working with trauma survivors in such a manner as to result in significant changes in the therapist's thoughts, behaviors, feelings, and relationships.

McCann and Perlman (1990) further suggested that, "The counselor's emotional responses to client's material is shaped by both [the] characteristics of the situation and the [counselor's] unique psychological needs and cognitive schemas" (p. 136). They suggested that counselors may experience either subtle or massive disruptions in their own schemas about the world and themselves while working with trauma survivors depending on the degree of discrepancy between the client's traumatic memories and the therapist's existing schemas.

\section{Cognitive-Developmental Correlates}

Cognitive strategies for processing discrepant information have been reflected in the psychological literature in a number of forms under the rubric of consistency theory (Brown, 1965) and reflected most often in the form of either a balance model (Heider, 1958) or a cognitive dissonance model (Festinger, 1957).

The primacy of changes in cognitive schemas, however, is probably associated most with cognitive-developmental theories which characteristically embrace this concept of schemas (Loevinger, 1987). From the cognitivedevelopmental perspective, every action requires some balance of assimilation and accommodation. To the extent that the existing schemas on an individual are sufficient for new materials, the information has been assimilated. To the extent that the schemas of the individual change in 
response to the new material, accommodation has taken place (Loevinger, 1987). The behaviors associated with vicarious traumatization or compassion fatigue described by McCann and Perlman (1990) and Neuman and Gamble (1995) could be re-framed as failures of accommodation.

Loevinger (1976) suggested that there are eight developmentally different stages or manifestations of ego development that individuals go through to achieve psychology maturity. These are the Impulsive, Self-protective, Conformist, Conscientious-Conformist, Conscientious, Individualistic, Autonomous, and Integrated stages. We might assume that the majority of counselors are drawn from a population of individuals that have average to above average levels of psychologically maturity. The Conscientious-Conformist, Conscientious, and Individualistic stages all have conscious preoccupations related to feelings, motives for behaviors, social problems, achievement, and inner life. In addition, the interpersonal style of each of these stages involves helping others, concern for communication, and resolving dependency as an emotional problem.

Loevinger (1976) noted that the distinctive mark of the Conscientious stage is having self-evaluated standards. Blanket approval and disapproval of people declines. People are seen as complex. "Individuals at this stage have long-term purposes, goals, and ideas. A negative aspect of this character type [however] is that the person may feel excessively responsible for others" (Loevinger, 1987, p. 228-229). Excessive responsibility combined with over-identification would seem to be essential aspects of compassion fatigue. Accordingly, there may be a relationship between stage of ego-development and susceptibility to compassion fatigue.

\section{Additional Susceptibility Factors}

Neuman and Gamble (1995) reported four factors in addition to one's stage of ego-development, however, that may increase novice counselors' susceptibility to being traumatized in their work. These include low professional status within the agency, anxiety related to professional viability, lack of access to professional mentor or role model, and the counselor's own personal history of traumatization. These factors will be discussed briefly.

The first two factors, low professional status and anxiety about maintaining employment are very often intertwined. Counselors at the bottom of the organizational hierarchy, either because they are newly hired or otherwise less experienced, often lack the social and technical support of their more seasoned colleges. Accordingly, new counselors and counselor trainees are particularly concerned about performance issues both for the sake of their clients and for their own present academic or future economic welfare. Low professional status thus contributes to anxiety related to professional viability.

Cherniss (1993) believed that individuals with high professional self-efficacy experience less job related stress than those with lower levels of professional selfefficacy. According to Cherniss, those with high professional self-efficacy were not only more resistant to burnout but were also capable of actually changing burnout prone environments. Although Cherniss did not address vicarious traumatization, it seems reasonable to assume that the notion of selfefficacy would also be worthy of exploration as a preventive factor. Increased social support could also aid in prevention as well.

The next factor listed by Neuman and Gamble (1995) was access to a professional role model or mentor. Although most counselors engaged in trauma work usually have access to supervision, every supervisor may not have a great deal of experience in trauma work.

However, perhaps the most significant factor increasing the novice counselor's susceptibility to compassion fatigue is her or his own personal history of traumatization (Neuman \& Gamble, 1995; Perlman, 1999). As noted earlier, many counselors have such a history. Elliot and Guy (1993) noted that many therapists are themselves survivors of early trauma and family disruption. More specifically, Kottler and Hazler (1996) estimated that over 6,000 clinicians are currently practicing while suffering from some type of mental or emotional impairment. For counselors who are themselves trauma survivors, the potential for compassion fatigue is certainly more probable because of their opportunity for a special identification with the client as well as their ambivalence about self-disclosure (Neuman and Gamble, 1995).

\section{Proactive Strategies}

\section{Education and Support}

The availability of consistent social support from the work environment is an obvious but often overlooked factor in the prevention of compassion fatigue. The clinical supervisor's support is essential during a time when almost all of the novice counselor's energy is 
devoted to the needs of others. The novice counselor may especially benefit from supervision that stresses tolerance for uncertainty and ambiguity, directly addresses transference and countertransference, and affirms the novice counselor's needs for both departmental and social support.

In the absence of consistent social support, novice counselors "will have difficulty taking risks in their work and tend to remain mired in a superficial advice-giving approach" (Neumann and Gamble, 1995, p. 343). As a minimal standard, all new counselors should be educated about compassion fatigue and its symptoms. This will at least allow them to recognize and understand some of the disturbing effects of counseling traumatized clients and to help them to develop the confidence to ask for assistance as they approach the limits of their professional knowledge and skills.

\section{Counselor Self-Care}

Just as counselors support clients in seeking balance in their lives, they also need to make a concerted effort to be at least as committed to their own health and well-being. Novice counselors, therefore, should also be instructed in self-care. Adequate self-care is the professional responsibility of each practicing counselor. If counselors do not care for themselves, they not only model abusive and self-destructive behavior to their clients, but they are also are at much greater risk of hurting their clients (Sheffield, 1998).

Adequate self-care involves setting and maintaining firm boundaries between work and home life; limiting exposure to traumatic media; developing, maintaining, and cherishing non-work interpersonal relationships; and maintaining physical health. Novice counselors may need assistance from her supervisor in finding ways to increase their knowledge, experience, and competence as a counselor without becoming overwhelmed by their work.

Adequate self-care also involves seeking additional clinical supervision and psychotherapy as needed. Novice counselors who experience compassion fatigue or burnout and therefore seek assistance through supervision or psychotherapy should not be considered to be defective. It is frequently the case that they will recover with proper treatment and support so it is important that counselor education programs see that these students are assisted rather than punished.

Finally adequate self-care involves becoming involved in activities that are centering, spiritual, or transcendental, and reflecting on the joys of being human (Perlman, 1999). It is very easy for novice or professional counselors to be come problem-oriented, diagnosis-driven, or casecentered. A very important aspect of supervision involves reminding the supervisee of the value of achieving and maintaining balance and perspective in one's life. Successful prevention of compassion fatigue involves a whole person approach. No facet of the individual should be omitted.

\section{Conclusion}

Traits that counselors commonly bring to the treatment process include the need to help others and the need to demonstrate competence. Counselors as a group tend to find meaning in their lives by helping others (Perlman, 1999). "The ability to oscillate between emotional connection and intellectual analysis enables [them] to use both empathic immersion and intellectual perspective to guide their behavior with [clients]" (Perlman, p. 91). The essential task of the counselor working with trauma survivors is to engage the client at his or her deepest level of despair without becoming self-absorbed to the point of denying the client's reality or failing to hear the client's voice. Part of the counselor supervisor's role is to help the novice counselor learn to do this.

The breadth and depth of the client's needs may provoke feelings of inadequacy in the novice counselor. Unexamined, these feelings may push the novice counselor to professional and personal over-extension. This ultimately leads to poor interpersonal relationships, burnout, and compassion fatigue. Perlman has suggested that the ultimate goal of treatment is to create a new existence for the client. This process can also profoundly change the counselor. Novice counselors need education, empathy, and support to function well in this process. Perhaps the most important preventive strategy the clinical supervisor can employ is to display accepting and non-shaming attitudes so that supervisees may feel safe enough to present their concerns.

\section{References}

Brown, R. (1965). Social psychology. New York: Free Press.

Cherniss, C. (1993). Role of professional self-efficacy in the etiology and amelioration of burnout. In W.B. Schaufeli, C. Maslach, \& T. Marek (Eds.) Professional burnout: Recent developments in theory and research (pp. 135-149). Washington, DC: Taylor \& Francis.

Elliott, D. \& Guy, J. (1993). Mental health professionals versus nonmental health professionals: Childhood trauma and adult functioning. Professional Psychology: Research and Practice, 24, 83-90.

Festinger, L. (1957). A theory of cognitive dissonance. Evanston, Illinois: Row, Peterson.

Figley, C.R. (Ed.). (1985). Trauma and its wake: The study and treatment of post-traumatic stress disorder. New York: Brunner/Mazel.

Forrest, L., Elman, N., Gizara, S., \& Vacha-Hasse, T. (1999). Trainee impairment: A review. Counseling Psychologist, 27, 627-687.

Heider, F. (1958). The psychology of interpersonal relations. New York: Wiley.

Herman, J.L. (1992). Trauma and recovery: The aftermath of violence. New York: Basic. 
Kottler, J. \& Hazler, R. (1996). Impaired counselors: The dark side brought into light. The Journal of Humanistic Education and Development, 34(3), 98-107.

Loevinger, J. (1976). Ego development: Conceptions and theories. San Francisco: Jossey-Bass.

Loevinger, J. (1987). Paradigms of personality. New York: W.H. Freeman.

Maslach, C. \& Jackson, S. (1986). Maslach Burnout Inventory, Second Edition. Palo Alto: Consulting Psychologists Press.

McCann, L. \& Pearlman, L. (1990). Vicarious traumatization: A framework for understanding the psychological effects of working with victims. Journal of Traumatic Stress, 3(1), 131-149.

Munroe, J.F., Shay, J., Fisher, L., Makary, C., Rappoport, K., \& Zimering, R. (1999). Preventing traumatized therapist: A team treatment model. In C. Figley (Ed.), Trauma and its wake (Volume III): Secondary traumatic stress disorder. New York: Brunner/Mazel

Neumann, D. \& Gamble, S. (1995). Issues in the professional development of psychotherapists: Countertransference and vicarious traumatization in the new trauma therapist. Psychotherapy, 32(2), 341-347.

Pearlman, L. A. \& Saakvitne, K.W. (1995). Trauma and the therapist: Countertransference and vicarious traumatization in psychotherapy with adult survivors of childhood abuse. New York: Norton.

Perlman, S. (1999). The therapist's emotional survival: Dealing with the pain of exploring trauma. Northvale, NJ: Jason Aronson Inc.

Perry, W.G., Jr. (1970). Forms of intellectual and ethical development in the college years. New York: Hold, Rhinehart \& Winston.

Sheffield, D. S. (1998). Counselor impairment: Moving toward a concise definition and protocol. Journal of Humanistic Education and Development, 37(2), 96-106.

Stadler, H.A., Willing, K.L., Eberhage, M.G., Ward, W.H. (1988) Impairment: implications for the counseling profession. Journal of Counseling and Development, 66, 258-260.

White, P. E. \& Franzoni, J. B. (1990). A multidimensional analysis of the mental health of graduate counselors in training. Counselor Education and Supervision, 30, 258-267. 